Financial Markets, Institutions and Risks, Volume 3, Issue 1, 2019

ISSN (online) - 2521-1242 ISSN (print) - 2521-1250

\title{
Behavioral Biases Influencing the Decision Making of Portfolio Managers of Capital Securities and Traders in Morocco
}

http://doi.org/10.21272/fmir.3(1).92-105.2019

\section{Hnaka Hadbaa}

$\mathrm{PhD}$ holder in Management Sciences, National School of Commerce and Management of Agadir, University Ibn Zohr, LARGE Laboratory, EDEMO Research Team, Morocco

\section{Rachid Boutti}

Professor, President of the Chair UNESCO Sustainable Development, Founder of LaRGe Laboratory, Director of the CREMA Indexed International Journal and Expert at the CNRS, Agadir, Morocco

\begin{abstract}
Behavioral finance is a new discipline that has emerged to explain the anomalies in the financial markets (ex: the succession of speculative bubbles and stock market crashes). It is based on two assumptions namely the irrationality of investors and limit arbitration. Behavioral finance is based on prospect theory and the psychological biases.

In this paper we will present first the behavioral finance and its state of research. Secondly, we will present the results of the survey that was conducted with a sample composed of managers of equity securities portfolios exercising in the management companies in Morocco and Moroccan traders and which deals with psychological biase that affect their decisions the most. The results showed that capital portfolio managers and Moroccan traders are influenced by psychological biases in their decision-making.
\end{abstract}

Key words: Behavioral finance, psychological biases, taking decision, irrationality of investors. JEL Classification: G4, G40.

Cite as: Hadbaal H., Boutti R. (2019). Behavioral Biases Influencing the Decision Making of Portfolio Managers of Capital Securities and Traders in Morocco. Financial Markets, Institutions and Risks, 3(1), 92105. http://doi.org/10.21272/fmir.3(1)92-105.2019.

(C) The Authors, 2019. This article is published with open access at Sumy State University.

\section{Introduction}

The classical or modern finance under the neo-classical economy was based on the maximization of utility expectancy, the hypothesis of lack of arbitrage opportunity and especially the assumption of efficiency of the markets constituting the core of financial theory. However, the succession of speculative bubbles and stock market crashes was the source of the criticism towards the postulate rationality-efficiency and led to the questioning of classical finance. In this sense, the psychological explanation of the financial markets led thereafter to the emergence of Behavioral Finance in the studies on finance which was developed from the perspective of the humanities. Behavioral finance, while drawing inspiration from psychology, could hardly neglect the fundamental work of the pioneers of modern portfolio theory such as Markowitz and Sharpe, but it has focused on individuals and ways of collecting and using information and has, thus, incorporated individual aspects of the decision-making process into financial markets.

This article will first report the theoretical generalities related to the birth of behavioral finance; its fundamentals to present then the most known psychological biases, namely, overconfidence, anchoring bias, herd behavior or sheep behavior, representativeness bias and mental accounting, in addition to a new bias embedded in the study of the cultural bias. Later, it will present the results of the study that focused on psychological biases that influence the decisions of managers of equity securities and traders.

\section{1- Theoretical part:}

\subsection{Presentation of behavioral finance}

It was at the beginning of the 1980s that a new approach, proposing to study the financial phenomena by including the behavioral dimension, was born with the first contributions of a small group of professors of finance, namely: Hersh Shefrin, Robert Schiller, Werner De Brondt and Richard Thaler. They focused on the study of investors' behaviors and market movements without any theoretical bias. They began to exchange 
their research with psychologists such as Daniel Kanheman and Amos Tversky; two specialists in the study of individual behaviors in risky environments. According to Stracca (2004), behavioral finance is a new trend that rejects Savage's axioms whose objective is the maximization of preferences considered as the main goal of an economic agent. Frankfurter and McGoun (2001), for their part, admit that investors behave like humans, individually or collectively (with their qualities and flaws), and not as a homogenous group of rational individuals as classic finance presents them. And since they are so, it should be necessary to study how they react and make their decisions. The fields of psychology, sociology and anthropology have presented different models of human behaviors that offer tools for analysts for a better understanding of market events.

After more than thirty-five years, behavioral finance or "La Finance Comportementale" has ceased to be a marginal research trend and has emerged as the most paradigm to replace the neoclassical approach that has dominated the "area" since 1950s. This modern approach, so-called Neoclassical, focused on two fundamental assumptions: the rationality of investors and the efficiency of market. Known by the weight of its two pillars, the standard approach has been able to model market balance at the micro level so that agents concerned with this balance reach their optimum with portfolios that maximize the profit-risk ratio. At the macroeconomic level, it has proved that market prices perfectly illustrate the fundamental values according to the availability of information. Behavioral finance, on the other hand, has taken a radically different approach. Its point of departure was to test the rationality of the agents and the associated axioms. The conclusions of psychologists and other members of this discipline were as follow:

- The axioms of independence and transitivity are often overwhelmed by individual decisions;

- Investors have a herding behavior;

- Investors do not follow the rule of BAYES.

- Investors are overconfident;

- Investors simplify complex choices with rules and shortcuts called heuristics ${ }^{1}$

Drawing on psychology, behavioral finance empirically observes the actual behavior of investors and compares them to price changes in the markets. These are the repetitions of observations that led to the criticism of the neoclassical theory inviting finance as a whole to change its vision.

Behavioral finance thus considers the study of the activity of the financial markets from the point of view of the social sciences by borrowing a broad repertoire of research methods and accepting the complexity of human behavior. Behavioral finance has not neglected the fundamental work of Markowitz, Sharpe, or other pioneers of modern portfolio theory, but has incorporated individual aspects of the decision-making process into financial markets. In other sense, it is interested in the individuals and the means to collect and use information.

According to Christophe SCHINCKUS (2009), «It should be noted that there is currently no true unified theory of behavioral finance. The current one is still unstable and incomplete». Schinckus also explains that despite the various researches carried out in this field as heterogeneous as they are, they all relies on three hypotheses.

The existence of behavioral biases: It is through the different observations made in the laboratory by cognitive psychologists that behavioral biases appeared. They constitute the fundamental hypothesis of behavioral finance. These biases account for the differences between the observed behavior of agents and the rational behavior on which the standard financial economy is based. Each individual has his own perception of things that gets simplified with heuristics. These simplifying heuristics represent an internal characteristic in all economic agents.

- The impact of environmental data on investors' decision-making: Classical finance describes the financial environment as being transparent, unlike the behavioral finance which assumes that the environment is opaque, which leads to perception bias.

- The hypothesis of inefficiency of the financial markets: inefficiency is opposed to the classical theory of finance and attacks the main foundation of the latter which is the rationality of the investors. Several studies

\footnotetext{
${ }^{1}$ A heuristic describes principles and methods that make it possible to formulate judgments or likelihood assessments in a simpler way. This concept is central in behavioral finance because it allows to understand how the operators deviate from the rational agent.
} 
Financial Markets, Institutions and Risks, Volume 3, Issue 1, 2019

ISSN (online) - 2521-1242 ISSN (print) - 2521-1250

have shown that individuals make mistakes in the way they process information. Classical finance is mainly criticized for its psychological dimension, in other words, for the so-called rational behavior of investors.

-The foundations of the behavioral theory: Behavioral finance is based on perspective theory and psychological bias. In this article, we will dive only through psychological purpose of the study that will be processed later.

-The heuristics and cognitive biases: Heuristics are strategies for simplifying the decision-making process. Without realizing it, human beings use it when faced with decisions whose conditions are uncertain (when the future is unpredictable) or complex (when the amount of information is very large). Decision makers often use these heuristics to make quick decisions. Shah and Oppenheimer (2008) define them as: «rules of thumb or mental shortcuts designed to reduce the effort involved in accomplishing a task, primarily by taking into consideration less information». Tversky and Kahneman (1974) state that «heuristics are certainly useful, but they sometimes lead to serious and systematic errors». They consider them as "prediction or estimation errors" which they refer to as bias. In literature, biases, which are usually assumed to be cognitive, are considered as reasoning errors or, more specifically, as errors in the processing of information. These errors are characterized by a distortion or deformation effect on the decision-maker's assessment of reality and his judgment.

The classical approach to decision-making explains that a cognitive bias lead, by definition, to a decision that is not rational because it is not based on valid or perfect information. The latter does not necessarily imply that the chosen decision is biased or has negative consequences. According to Bazerman (1990), « the ultimate success or failure of a decision usually depends on several factors, some of which are beyond the control of the decision-maker». The theory of heuristic principles, developed by Tversky and Kahneman (1974), states that agents do not possess the cognitive abilities required to be able to make decisions on the financial markets in a rational way. These individuals operate shortcuts of reasoning to simplify reality in order to make more comprehensiblemodels. Their choices are not always in conformity with what is foreseen by the hypothesis of perfect rationality. According to Tversky and Kahneman (1974), a heuristic is a cognitive strategy that saves time and makes inferences acceptable to the individual although they may be wrong. When making decisions, individuals opt for simplifying rules instead of embarking on the proper evaluation process. In this sense, the heuristics studied by Tversky and Kahneman (1974) are: the representativeness heuristic, the anchoring heuristic and the availability heuristic.

\section{-The representativeness heuristic:}

In a complex situation of decision-making, individuals often refer to mental shortenings rather than carrying out lengthy analytic treatments as stated by Yates (1990). Representativeness is the generalization of a situation from a particular known case. Indeed, individuals tend to evaluate the occurrence of a certain future event by the degree to which it resembles a recent observed phenomenon. Kahneman and Tversky (1974) define the basic assumption on which the representativeness heuristic is based: "The agents evaluate the probability of an uncertain event or sample by its degree of similarity between the fundamental properties of the sample and its parent population, and by the way in which it reflects the salient features of the process by which it has been generated». In other words, if individuals base their decisions on similarities, they diverge from rational reasoning. These authors explain that a person follows the representativeness heuristic if he evaluates the probability of an uncertain event or a sample by the degree to which it is similar in its essential properties to the mother population, and respects the main characteristics of the process by which it is produced. Essentially, the representativeness bias is based on stereotypes to form irrational opinions quickly (Shefrin, 2005). Based on representativeness, investors tend to overlook the basic probabilities and follow the similarities observed with other typical or representative events. The representativeness heuristic is very important but can nevertheless cause serious bias like the neglect of base rates and of sample size.

Base rate neglect: This bias explains the tendency of individuals to not consider all available information and to miss the statistical data and probabilities of a situation by choosing elements that are irrelevant but easier to access.

Neglect of sample size: The individual here tends to generalize a situation from a small sample that he considers to be representative of a larger set. The individual often neglects considering the "sample size" factor. In his book "Behavioral Finance," Susskind takes the example of an analyst who gives a four-times in a row forecast that has been confirmed by the market, proving that he is part of the "good analysts" group, and that these tips are not representative of all "bad advice". Debondt and Thaler (1985) claim that this 
Financial Markets, Institutions and Risks, Volume 3, Issue 1, 2019 ISSN (online) - 2521-1242 ISSN (print) - 2521-1250

heuristic leads to phenomena of over-reactions of stock prices: individuals believe that a stock price that shows a constant upward trend represents a good approximation of its future course. This will generate an over-reaction of analysts following the positive results.

-Anchoring bias: Hirsheilfer (2001) defines anchoring as "a phenomenon in which agents tend to be excessively influenced in their estimates by an arbitrary quantity mentioned in the formulation of the problem, even when these quantities are clearly meaningless". According to Edward (1968), «it is a mental process by which people give more importance to their previous views or predictions to the detriment of new information». This bias describes the fact that individuals base their estimates on a given problem based on a data taken as reference. Indeed, these individuals overweight past information to the detriment of recent information. This implies that the weight they assign to past data is too high and that new information cannot have an impact on decision-making. Mussweiler and Strack (2000) addressed the question of the relationship between uncertainty and anchoring phenomena. They said that when uncertain individuals have to analyze a situation, they tend to build their judgment based on familiar reference points. In 2002, Mussweiler and Welch show that investors tend to consider stock market extremes as benchmarks in their analyzes.

-Availability heuristic: The heuristic of availability was also put forward by the famous authors Kahnman and Tversky in 1974. This is a method of reasoning based on the immediate availability of information. Individuals who use this heuristic tend to associate a frequency or probability with an event based on facility with which examples or associations of such an event come to mind (Tversky \& Kahneman, 1974). This heuristic refers to the ease with which examples (or identical cases) are available in memory. Pouget (2000) states that «Subjects using this heuristic rule evaluate the probability of an event by the ease with which examples or similar cases come to mind. » Barber and Odean (2008) studied the impact of published information on the behavior of individual and institutional investors. They showed that when investors decide to buy stocks, they tend to look only at stocks that have recently caught their attention (stocks with high trading volumes, stocks that appeared in the media, high yield securities). The authors also showed that institutional investors are less sensitive to availability heuristics than individual investors.

- Overconfidence: Several studies in economics have shown that individuals tend to overstate their abilities and knowledge which leads them to underestimate the risk of a random variable. This is known as overconfidence bias. This latter is manifested by a very natural tendency to think that one's abilities (or knowledge) are more extensive than they actually are $^{6}$. Debont and Thaler argue that this is the most important discovery in the field of decisional psychology. Overconfident individuals believe much more in their own evaluation and do not care about the thoughts of others, which implies underestimating the variance of their precision error. According to Shiller (1998), individuals will continue to make the same mistakes as when they are repeated and will have important consequences. This will lead them to review their behavior, which will certainly imply a lack of confidence. Several studies have been done to determine the origins of this overconfidence and we distinguish:

The over-optimism: In fact, the research carried out in this direction has shown that man is by nature known for his optimistic nature and will tend to overestimate the expectations of the assets gains he holds in his portfolio. "The over-optimism is a feeling related to the attribution of greater chances to the realization of the favorable events compared to the objective probability of occurrence" (Ben Bouheni, 2009) ${ }^{7}$. The over-confidence pushes individuals to take risks in the markets. They overestimate their own abilities. This generalized tendency brings with it an illusion of controlling events.

The better than average effect: According to Greenwald (1980), Taylor and Brown (1988), overconfidence can be manifested by an overestimation of one's own abilities compared to others, sometimes referring to "the effect better than the average". Several studies have shown that people often rate themselves as "above average", that is, smarter, more athletic, healthier, etc., than the average (Alicke et al., 1995, Heine and Lehman, 1997; Kruger and Dunning, 1999). This unrealistic positive self-esteem may lead to unrealistic optimism about the chances of achieving positive results (Weinstein, 1980).

-The poor/bad Calibration: Another manifestation of overconfidence is the tendency to overestimate the accuracy of the information which is known as poor calibration. Several studies have been conducted on this matter. In this sense, we quote as an example:

-The study carried out by Sol and Klayman (2004) showed that the bad calibration is identified by very narrow confidence intervals.

- The work done by Benos, Odean, Daniel et al in 1998, showed that in a context of financial market with 
Financial Markets, Institutions and Risks, Volume 3, Issue 1, 2019

ISSN (online) - 2521-1242 ISSN (print) - 2521-1250

information asymmetry, the bad calibration leads to excessively aggressive transaction strategies and poor performance.

- The study developed by Vissing-Jorgensen (2003) showed that investors in their anticipation of the expected gains use "the law of small numbers" and are also subject to auto-attribution bias.

-Overconfidence in the financial markets: On the stock market, overconfidence means that investors are sure to understand the market well and are able to anticipate its short- term fluctuations: the sale and purchase of securities is very frequent because one believes he knows the securities that the market will favor in the short-term. In portfolio management, a person takes a position without first conducting detailed analysis, because overconfidence often results in the non-use of available information. It is also possible that the intensive use of it can lead to overconfidence. In addition, the positions taken are even more risky as their last operations proved more successful.

-The mimetic behavior: Mimicry, also called "sheep behavior" or "herd behavior", is defined as a set of behaviors that exhibit a correlation. Sheep behaviors are equated with the opposite of overconfidence. The investor tends to follow the actions of others without understanding them. In some market environments, this type of behavior is rampant. Due to the reception of correlated information, many investors can follow the trend and buy the same securities. There are two types of mimetic behavior: "fallacious imitation" and "intentional mimicry". The first occurs when agents hold the same information and make similar decisions, but independently. As for the second, it occurs when the agents intentionally imitate the behavior of other agents.

- Loss aversion: According to Mickaël Mangot (2004) ${ }^{8}$ : «the tendency to behave differently when one is in a loss or a gain state is stronger as it results from the observations of a loss aversion which makes individuals consider them twice as painful as the gains are pleasant. » He adds that this discovery goes back to Daniel Kahneman and Amos Tversky who have treated the basics of perspective theory that explains the rules of decision-making in risky environments. Loss aversion explains why investors tend to keep losing stocks, because if they sell them to buy another one, and they gain less value, they will only receive half of the disappointment caused by the loss of the first stock. Loss aversion is probably the most fundamental concept to account for stock market behavior. It is a behavior that attests the almost unanimous resistance to take losses and impatience to realize its gains. The investor, for an amount, gives up investing because he believes that for the same title/stock, even if the expectation of earnings is clearly positive, there is possibility to lose. The investor in this case of behavior, also thinks that it is wise to quickly take gains on the stock market because the moods of the market change very quickly. Once purchased, the investor no longer follows the news of his title/stock, and this is also the case of the securities that were failed to buy.

-Mental accounting: Thaler in 1985 defines mental accounting as the tendency of individuals to classify goods in different mental compartments. Individuals focus primarily on the relevance of each individual decision and do not care about the consequences of their decisions. They create for each good a mental account to which they assign a code. In mental accounting, the criterion that individuals take into consideration is the utility provided by this good. Thaler in 1985 identifies two types of utility: the acquisition utility that measures the utility of a good in relation to its purchase price and the transaction utility that measures the difference between the purchase price and the reference price set by the individual. In the case of transactional utility, the individual buys the good only when the price to be paid is less than or equal to the reference price. To study the effects of mental accounting, Shefrin and Thaler (1988) proposed a classification of US household income according to the criterion of the availability of money. They showed that incomes are classified separately into three different mental accounts: the current wage (current assets account: money in hand and chequing account); investment income (the current assets account: savings account, booklets, etc.); future income that is used to prepare for retirement. Shefrin and Thaler (1988) added that individuals spend money differently according to the category in which they associate it with. They showed that for the current asset group, the average proportion to spend is close to 1 while it is almost 0 for the third category. Every dollar in the first category is spent while every dollar in the last category is definitely saved (until retirement). In the financial markets, investors decide for each security taken individually instead of taking the entire situation into account as to its final use. An investor who negotiates separately titles can be led to sub-optimal portfolio diversification and therefore to underestimate its performance (Bouattour, 2012) ${ }^{9}$. Shefrin and Statman (2000), developing Behavioral Portfolio Theory, provided an explanatory framework of investment choices that are totally different from those of the Markowitz average - variance model (1952). The behavioral portfolio theory explains how investors build their portfolios. According to these authors, the asset portfolio takes the form of 
a pyramid and adapts with the behavior of an investor who follows the concept of mental accounting, which is the management of portfolio. Investors have a mental account for each investment objective so that the overall portfolio is formed from the piling up of mini- portfolios determined by their expected level of risk and gain. These mini-portfolios are not optimal in the sense of Markowitz (1952) and the correlation between different mental accounts is also neglected.

\section{-The status-quo bias:}

Mangot (2004) defines the status-quo bias as paralysis in the decision. It is the tendency to leave things as they are or unchanged as the decision to change appears as a source of risk more than as a source of benefits. Several areas state that the adoption of this bias implies choices that are not that rational. As humans, we often feel apprehensive about change, which leads us to make choices that ensure things stay the same, or change as little as possible. When an investor makes a decision in his own interest, he will tend to do nothing because of the status-quo bias. Financial actors prefer to keep the investments that already belong to them. Deciding to change investment shows that previous investment decisions were bad choices."This is especially the case when stock prices go down. The status-quo bias implies preferring the default choice, which is often a noaction option "(Douret, 2015). Shafir and Tversky (1992) in one study concluded that while the number of attractive alternatives is high, this implies a delay in decision- making. In other words, when the investor is faced with several investment choices, the decision-making task can become overwhelming. As a result, some investors prefer to refrain from any changes.

\section{Methodology:}

The purpose of this article is to determine the psychological biases that influence investors' decisions on the Moroccan stock market. We opted for a quantitative study based on a questionnaire. Regarding the selection of the sample, the method of judged choices was used to determine the sample of portfolio managers of the equity securities of the management companies and the method of sampling networks or snowball for traders of the Moroccan stock market. These methods allowed us to choose very precisely the elements of the sample, while respecting the criteria that were set in this research. The choice of the sample is motivated by the weight of the operations carried out by these investors in the Moroccan market.

In fact, according to AMMC ${ }^{1}$ figures for the first quarter of 2015 , the volume of purchases and sales made by mutual funds and individuals reaches $35 \%$ and $10 \%$ respectively of the Moroccan stock market's purchases shares and $31 \%$ and $10 \%$ respectively of sales shares in the same market. This reflects their influence on the Moroccan stock market and hence the interest of their choice in this study.

The goal, as mentioned earlier, is to determine the psychological biases that influence investors when making decisions. for this purpose, we contacted 45 people to answer our questionnaire and relied on the website of the AMMC (Autorité marocaine des marchés de capitaux) (Moroccan Authority of Capital Markets) to determine all management companies operating in Morocco. Regarding Moroccan individual traders, we relied on the network of a trader in the Casablanca Stock Market by putting the snowball method into practice to reach other traders. The questionnaire administered for the collection of information was structured in such a way as to allow us to know and to detect the socio-professional characteristics of the managers (age, type and level of training, experience ...), as well as the behavioral biases involved in managing the portfolios. The studied biases are: loss aversion, sheep behavior, overconfidence, mental accounting, anchoring, cultural bias and representativeness, all of which are measured by 5-point Likert scales or scenarios. After administering the questionnaire, we ended up using 30 questionnaires only, since the rest of the resource persons contacted refused to answer them, which gives us a response rate of $66 \%$ of the chosen statistical universe. For the collection of answers, we used several modes of administration, namely the direct administration and the faceto-face interviews, questionnaires filled by telephone and questionnaires filled by e-mail.

\section{Processing the collected data:}

As for the analysis of the data, the exploitation and the interpretation of the collected data were carried out by means of SPHINX, SPSS and Smart PLS software. The first analysis carried out is the validity test in order to verify whether the purpose of the instrument is the same as that fixed for the study. In other words, it is a

\footnotetext{
${ }^{1}$ The AMMC is the Moroccan authority for capital markets. Its role is to protect savings invested in financial instruments, ensure equal treatment of savors, transparency and integrity of the capital market and investors' information; Ensure the proper functioning of the capital market and ensure the application of legislative and regulatory provisions; Ensure the control of the activity of the various organizations and persons under its control; ; Ensure respect to the current legislation and regulations relating to the fight against money laundering, by the persons and the organisms under its control; Contribute to the promotion of the financial education of savers; Assist the government in capital market regulation.
} 
matter of judging the relevance and the validity of the measuring instrument used. The validity of the construct is usually used if the study is about an abstract domain that is difficult to specify. It is defined by two concepts; the validity of convergence and the validity of divergence. The validity of convergence (Midi, 1996) indicates that the measurement of a construct is independent from the measurement process that has been followed. That is to say, that two measurements by different instruments of the same concept must lead to the same result. The technical principle is based on a correlation calculation between the results of the study to be validated and the results of a valid study on the same field. Both instruments are used simultaneously on the target population. We, then, test the hypothesis according to which the results of the study to be validated are correlated with the results of the reference study. The divergence validity (Midy, 1996) ${ }^{14}$ verifies that the measured construct does not overlap with another existing construct. In this case, either the two constructs actually concern the same domain and they are, therefore, redundant or they do not cover it. In this case one of the two constructs is poorly specified. The technique is based on the same principle of correlation, but from a valid study on a different field. Afterwards, we test the hypothesis according to which there is no correlation between the two results. The second test is of reliability. Validity is a necessary but insufficient condition to justify the relevance of a questionnaire. After ensuring that we are targeting the right target, we must be able to reach it on a regular basis. Concerning reliability, when the random measurement error is small, the measurement is said to be reliable. The reliability of a measuring instrument determines its ability to reproduce the same results if it is administered several times to the same population. To test reliability, we refer to Cronbach's alpha parameter, which measures the internal consistency of the items that make up each dimension in the concepts.

Recall that in this research we decided to study the psychological biases influencing the decision-making of investors in equity securities. The analysis of the relations between the variables of our model will be made by the recourse to the models of the structural equations. This latter allows on the one hand to validate the measurements, and on the other hand to study the relationships between the variables of a model. The modeling of structural relationships is done by linking unobservable constructs; it includes several statistical approaches, including the PLS (Partial Least Squares) iterative models. It is an iterative algorithm with an alternate estimate of latent variables as a function of each sub- model. In other words, it allows the estimation of complex causal relationships between latent variables measured through observed variables called manifest. In this study, there will be a set of constructs or indicators that help explain the influence of the latent construct and determine their impact on decision-making. In this case, our measurement model is part of a reflective logic. the validity of the measurement model will be, therefore, ensured by studying the convergent validity and the discriminant validity of the items and then studying the reliability of the concepts and the measuring instrument. Below is the proposed research model for studying the link between the different psychological biases called indicators and the latent construct -namely, decision-making- and using the PLS approach. This latter represents a tool adapted to the relational model test targeted by this research. The table below presents all the variables: explained and explanatory.

Table 1. Synthesis of Variables in the Econometric Model

\begin{tabular}{|l|c|l|}
\hline \multicolumn{1}{|c|}{ Entitled } & Code & Nature \\
\hline Decision making & PD & Explained Variable \\
\hline Cultural bias & C & Explanatory variable \\
\hline Status quo bias & STAT & Explanatory variable \\
\hline Representativeness bias & REP & Explanatoriable \\
\hline The mimetic behavior & MOUT & Explanatory variable \\
\hline Mental accounting & CM & Explanatory variable \\
\hline Loss aversion & A & Explanatory variable \\
\hline Overconfidence bias & EC & Explanatory variable \\
\hline The anchoring bias & ANC & Explanatory variable \\
\hline Risk taking & PR & \\
\hline
\end{tabular}

Source:

The following equation system materializes the econometric model used as a test for the structure model.

$$
\left\{\begin{array}{l}
\text { Prise de décision }=\alpha_{1}+\alpha_{2} \cdot A+\alpha_{3} \cdot E C+\alpha_{4} \cdot A N C+\alpha_{5} \cdot S T A T+\alpha_{6} \cdot C M+ \\
+\alpha_{7} \cdot \text { MOUT }++\alpha_{8} \cdot C M+\alpha_{9} \cdot C+\alpha_{10} \cdot P R+\alpha_{11} \cdot G+\alpha_{12} \cdot H I+\alpha_{13} \cdot A G E++\alpha_{14} \cdot E M+ \\
\alpha_{15} \cdot F O R++\alpha_{16} \cdot D I P+\alpha_{17} \cdot E X P+\alpha_{18} \cdot I N F+\alpha_{19} \cdot T A+\varepsilon
\end{array}\right.
$$




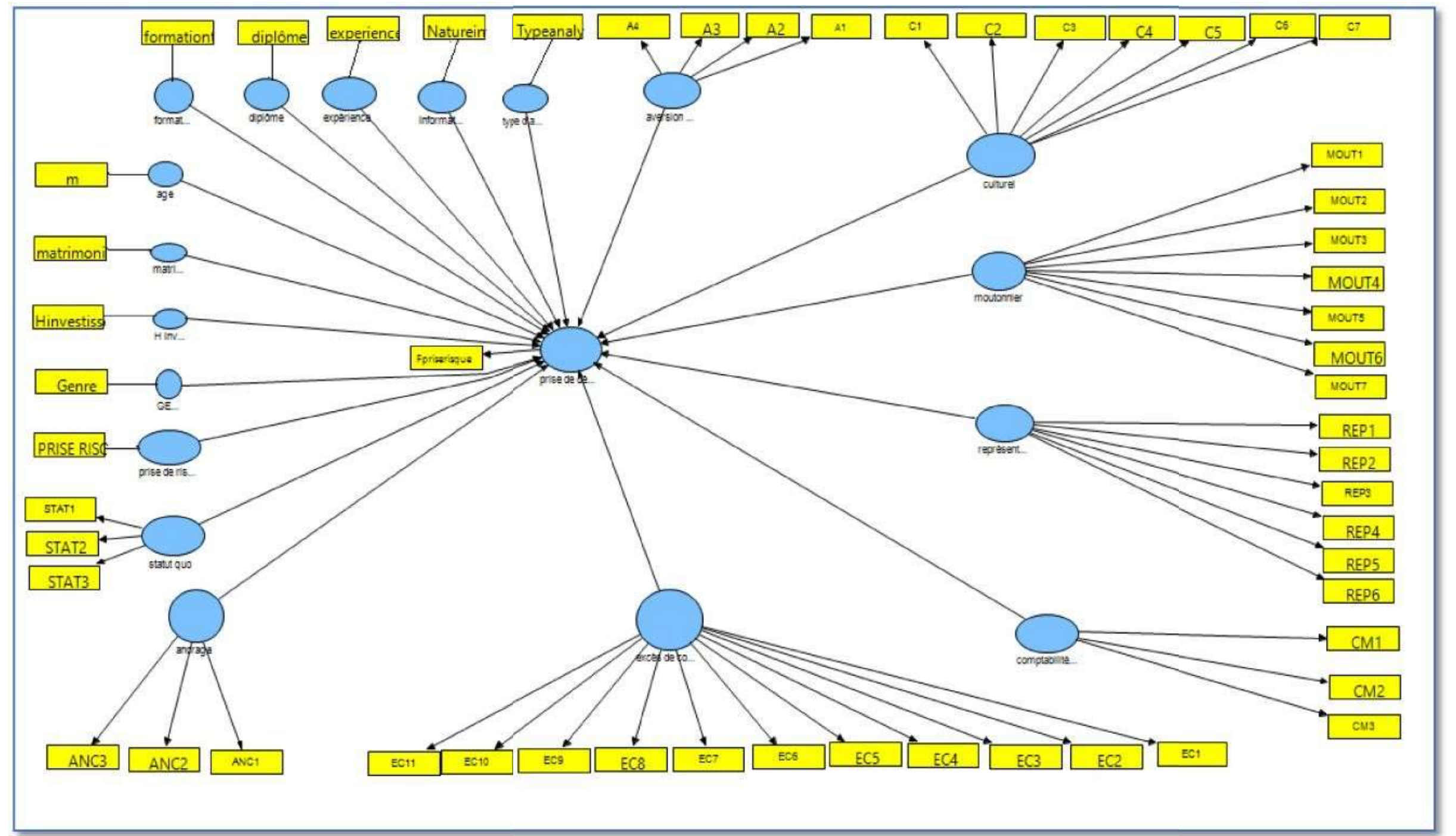


Financial Markets, Institutions and Risks, Volume 3, Issue 1, 2019

ISSN (online) - 2521-1242 ISSN (print) - 2521-1250

\section{Results and analyzes}

3.1. Model adjustments and explanatory analysis. The table below summarizes the results of validity and reliability tests using exploratory factor analysis and confirmatory factor analysis, respectively.

The first AFE analysis makes it possible to clear descriptive information. In this phase, the goal is to test the validity and reliability of the concepts and the measuring instrument. In fact, the factorial analysis of the correspondence makes it possible to eliminate the items which are badly represented during the extractionThe aforementioned decision rule states that the construct will be considered to have a "good" convergent validity when the correlation coefficients between its dimensions are positive and statistically significant, and when the factorial axis shares with its dimensions are at least half of the variations (while accepting the factorial transformation by a value at least equal to 0.5 ). Regarding reliability, the construct will be considered reliable through the internal consistency of the scale by the Cronbach's Alpha index which must be greater than 0.7. The analysis of the results by the concept of decision making will start. It was operationalized using 4 items. The exploratory factor analysis showed that even with the two remaining items, it is impossible to operationalize this concept. The result shows a $25 \%$ variability of the two items with insufficient internal consistency displaying a Cronbach's Alpha of 0.40 . The second concept is that of information as we operationalized it with 9 items of which 4 are considered representative of the concept. Loss aversion, as for it and with the 4 items attributed to it of which $2 \mathrm{kept}$ after the extraction of the components, was poorly represented since the quality of the representation is below the threshold of 0.5 and the Cronbach's alpha is 0.39 . The results of the extraction of the components of other constructs, namely the anchoring bias, the status-quo bias, the perception of risk and the mental accounting, also showed that their items were poorly represented. The overconfidence bias, and with these 11 items, can be operationalized with 4 items that show a total explained variance of $60.07 \%$ and a Cronbach's alpha of 0.7 . This is the same case for the sheep behavior that was operationalized using 7 items and the representativeness bias with its 6 items and whose extraction revealed that the items kept after extraction that were 2 and 4 respectively are representative of concepts. In fact, the results show percentages of variability of $66.77 \%$ and $50.99 \%$ respectively and Cronbach's alpha of 0.78 and 0.80 respectively. As the exploratory factor analysis remains insufficient to validate this research model, and since it is based on descriptive methods, it must be complemented by a more robust confirmatory factor analysis. A reminder, in the AFC, we test the validity and reliability of the concepts and the instrument with explanatory methods. We examine the convergent validity by the Average Variance Explain (AVE), this indicator must be at least equal to 0.5: which means that the construct shares more than $50 \%$ of its variance with its measurements. In other words, the measurement indicators account for a very large part of the variance of the construct. AFC also allows us to examine the divergent or discriminating validity that represents the ability of a measure to generate results different from the measures of the other constructs. Confirmatory factorial analysis also allows the reliability or consistency of the measuring instrument to be examined on the basis of the Cronbach's alpha index, which must be greater than 0.7, and the Composite Reliability Index which also must be greater than 0.5 . The role of reliability is to determine if the scale of measurement will not be biased if we repeat the study several times and if we change the structure of the sample. this study shows that the AVE is greater than 0.5 for all the variables, which explains the consistency between the items and their variables. In fact, the value of the AVE of the different concepts varies between 0.51 and 1. The composite reliability index which provides additional support for reliability is also greater than 0.5 for all the variables, and its value varies between 0.61 and 1. Finally, Cronbach's Alpha also respects the condition, but not for all variables, since loss aversion, anchor bias, and mental accounting display values less than 0.7 . From the results obtained, we can confirm the quality of the measuring instruments used to study the explanatory variables and the variables explained. After having tested the reliability and the validity of each selected dimension, we can finally 
summarize the results obtained in the table below, and present our validated research model under Smart PLS.

Table 2. Synthesis of assessment of the quality of measurement scales

\begin{tabular}{|l|c|c|c|c|}
\hline Variables & Items code & Number of items selected & AVE & Cronbach's Alpha \\
\hline Decision making & Prise de décision & 1 & 1 & 1 \\
\hline Informations & Nat info & 1 & 0.51 & 0.16 \\
\hline Loss aversion & A2 & 2 & 0.62 & 0.85 \\
\hline Overconfidence & $\begin{array}{c}\text { EC2 EC3 EC4 EC5 } \\
\text { EC8 }\end{array}$ & 4 & 0.51 & 0.05 \\
\hline Anchoring bias & $\begin{array}{c}\text { ANC2 } \\
\text { ANC3 }\end{array}$ & 2 & 0.87 & 0.85 \\
\hline The mimetic behavior & $\begin{array}{l}\text { MOUT4 } \\
\text { MOUT6 }\end{array}$ & 2 & 0.55 & 0.19 \\
\hline Mental accounting & $\begin{array}{c}\text { CM1 } \\
\text { CM2 }\end{array}$ & 1 & 0.56 & 0.81 \\
\hline Representativeness bias & REP1 REP2 REP4 REP5 & 4 & 0.80 & 0.78 \\
\hline Status quo bias & $\begin{array}{c}\text { STAT2 } \\
\text { STAT3 }\end{array}$ & 2 & 1 & 1 \\
\hline Risk taking & Prise de ris & C2 & 0.68 & \\
\hline Cultural bias & C4 C5 & 3 & & 0.81 \\
\hline
\end{tabular}

We note that the conditions required to validate our measurement model seem to be assured as well as a homogeneity of the scales. Especially since the convergent and divergent validity of all scales of measurement that have been proposed shows significant results. We were able to set our measurement model which represents all the explanatory variables. The figure below shows the measurement model that was designed with SMART PLS software.

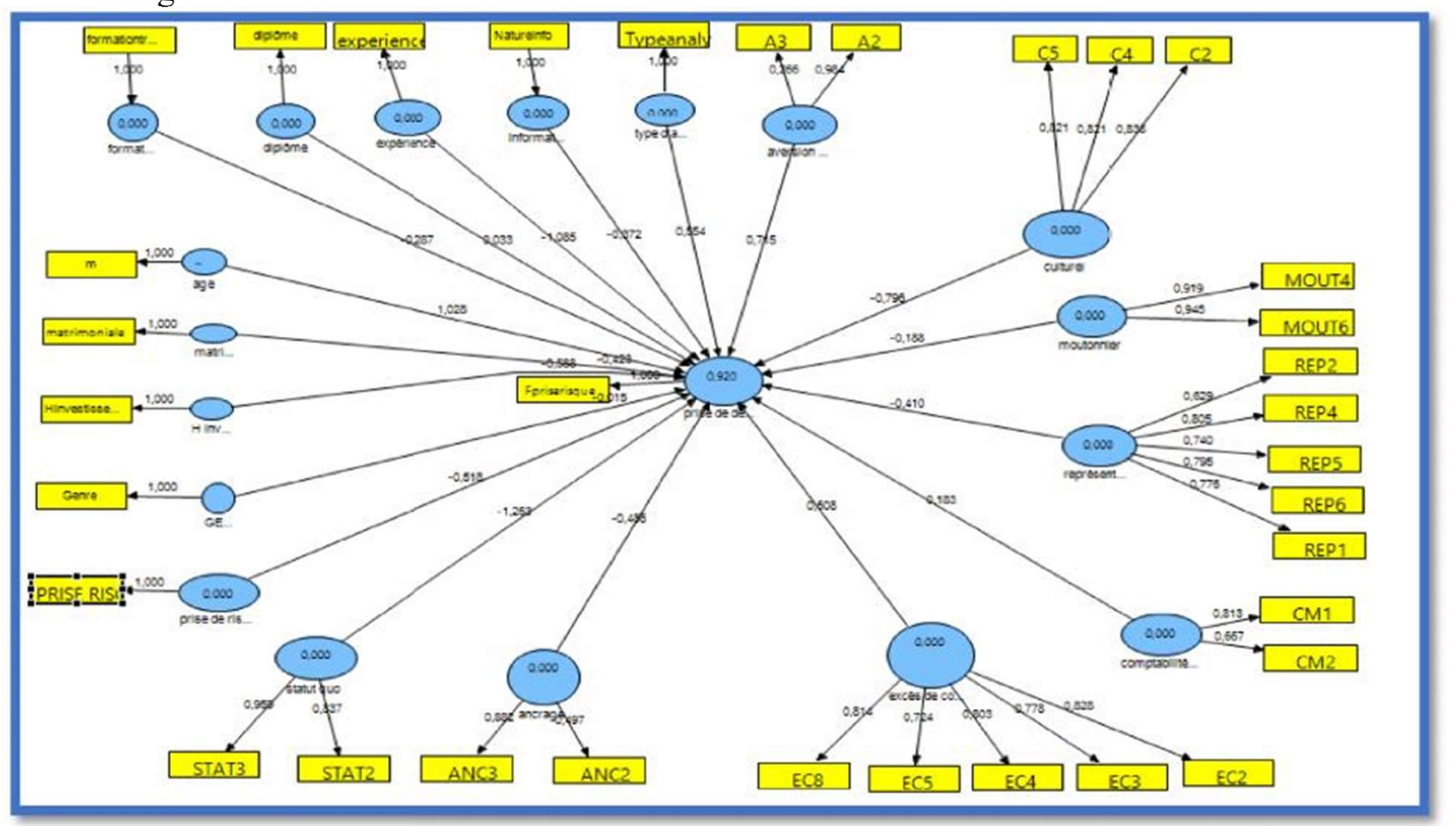

Figure 2. Measurement model adjusted by SMAT PLS software

\section{Evaluation of the structural model: empirical validation of the hypothesis}

3.2. Presentation of models for evaluating the quality of the structural model. After having verified the validity and the reliability of the scales of measurement, we will focus now on the study of the causal relation between the different variables of this study. the goal is to check whether or not there is a relationship between psychological biases and decision-making. The purpose is to confirm or refute this relationship among investors of equity securities in Morocco. This study is known as the validation of the structural model. To do so, we analyzed the links between the measurement indicators and the constructs. This is a vital approach that will allow us to validate our hypothesis. In this sense, we proceed to confirm the latter on the basis of the importance of the significance of the structural relationships obtained. Using the PLS method, the quality 
Financial Markets, Institutions and Risks, Volume 3, Issue 1, 2019

ISSN (online) - 2521-1242 ISSN (print) - 2521-1250

of the structural model is measured by a coefficient of determination $\mathrm{R}^{2}$, it informs on the contribution of each explanatory variable to predict the explained variable. In other words, this coefficient makes it possible to study the proportion of the variance of $Y$ that can be predicted by the function X. Since this coefficient alone does not allow us to measure the quality of the measurement model, we found it advisable to accompany it by determining the coefficients of the $\beta$ paths, also known as structural coefficients or standardized regression coefficients. These coefficients make it possible to determine the degree of importance of the effects that can be measured by them. It clarifies the meaning and strength of the relationship between the predicted variable and the predicator. Its value varies between -1 and 1 and the closer it is to 0 , the more the relationship is considered less strong. When the value is positive, it means that the two variables vary in the same direction. If not, it means that the variables vary in the opposite direction. This coefficient is determined by the Bootstrap method which aims at maximizing the variable explained by the explanatory variables. After the determination of the two coefficients of determination $\mathrm{R}^{2}$ and the coefficients of the paths $\beta$, comes the step of calculating the statistical significance of the values and which is counted by the Student test thanks to the Bootstrap method. The purpose of this test is to estimate a structural model that allows us to determine the relations that are supposed to exist between the latent constructs using the two coefficients and the Student test that we presented previously. The importance of the significance of the relations obtained will confirm or invalidate our hypothesis. Below are the results obtained using the Smart PLS logician:

Table 3. Synthesis of assessment of the quality of measurement scales

\begin{tabular}{|c|c|c|c|c|}
\hline Variables & Coefficient $\beta$ & Variance $\mathrm{R}^{2}$ & T student & Significance of effects \\
\hline Decision making & & 0.92 & & \\
\hline \multicolumn{5}{|c|}{ Explanatory variables } \\
\hline Loss aversion & 0.715 & & 2.78 & $\mathrm{p}=0.01 * * *$ \\
\hline Overconfidence & 0.508 & & 2.46 & $\mathrm{p}=0.05^{* *}$ \\
\hline Anchoring bias & -0.486 & & 3.51 & $\mathrm{p}=0.01 * * *$ \\
\hline Mimetic behavior & -0.188 & & 1.71 & $\mathrm{p}=0.1^{*}$ \\
\hline Mental accounting & 0.183 & & 1.56 & Not significant \\
\hline Representativness bias & -0.410 & & 0.98 & Not significant \\
\hline Status quo bias & -1.253 & & 3.99 & $\mathrm{p}=0.01 * * *$ \\
\hline Risk taking & -0.518 & & 3.36 & $\mathrm{p}=0.01 * * *$ \\
\hline Cultural bias & -0.796 & & 1.83 & $\mathrm{p}=0.1^{*}$ \\
\hline
\end{tabular}

From the table above, we can determine the relationships and structural links that explain the impact of the psychological biases on decision-making among portfolio managers of equity securities. When reading the table, we find that the $\beta$ pat coefficients take positive and other negative values. Decision-making is explained by the explanatory variables that display a positive $\beta$ coefficient, namely loss aversion $(\beta=0.715)$, overconfidence $(\beta=0.508)$ and mental accounting $(\beta=0.183)$. This explains why these variables have a very strong linear relationship with decision-making, while other explanatory variables display negative values, which explains their negative impact on decision-making. It includes anchoring bias, sheep behavior, representativeness bias, status-quo bias, risk taking and cultural bias. Similarly, for control variables, those with a very strong linear relationship to decision-making are age, diploma and type of analysis, while the rest of the control variables have a negative impact on decision-making. The T analysis of Student has positive and very significant values concerning all the psychological biases that affect decision-making. Thus, we find that most values are greater than 1.64 with a significant probability of the order of 0.1 with the exception of the representativeness bias that displays a value of 0.98 and the mental accounting bias that displays the value of 1.56. This means that the representativeness bias has no impact on the decision-making of portfolio managers of equity securities in Morocco. Regarding the psychological biases that affect decision-making the most, we have the status-quo bias $(\mathrm{T}=3.99)$, followed by anchoring bias $(\mathrm{T}=3.51)$, loss aversion $(\mathrm{T}=2.78)$, overconfidence $(\mathrm{T}=2.46)$ etc. As for the bias control, we can conclude that those who have an impact on decision-making are the investment horizon, age, experience and training.

The analysis of the coefficient of determination $\mathrm{R}^{2}$ for the whole results emanating from our analysis is of 0.92 which explains that all the studied variables, namely the psychological biases, the information, the diploma, the experiment etc, explain $92 \%$ of the variance of the variable explained which is the decisionmaking. While psychological biases alone can explain $77 \%$ of the decision-making. We can emphasize that this result confirms the existence of the psychological biases that intervene and affect the decision- making process of managers of portfolio securities in Morocco. Every human being has the mental shortcuts they use when making decisions and Moroccan portfolio managers are no exception. The difference that exists is that 
among these biases, there are those that can affect positively like loss aversion, decision-making, and others that may negatively affect it such as herding behavior, cultural bias, anchoring bias etc. Even the cultural bias that we have added that is not part of the psychological biases in theory influences the decision-making of portfolio managers in Morocco.

We can thus conclude that the psychological biases that influence the decision-making of the managers of equity securities are: anchoring bias, status-quo bias, sheep behavior, mental accounting, cultural bias, overconfidence bias and loss aversion, with the exception of representativeness bias that does not occur in the study sample.

\section{Conclusion}

For several decades, financial theory had been built around the assumption of the economic rationality of agents. It was based on three fundamental elements, namely: the maximization of utility expectancy, the assumption of market efficiency and the absence of arbitrage opportunity. These three pillars have led to a deeper understanding of the functioning of markets, price developments and valuation of financial assets. Portfolio management models were subsequently developed, based on portfolio theory and valuation models for derivative assets. They represent a proof for the theoretical advances, but also for the transfer to the professional world of university researches15. From the 1950s, several troubling findings emerged, leading to the questioning of the theory of the efficiency of the financial markets. Investors do not look like "homo economicus" who are described as intelligent economic agents capable of making rational choices without being influenced by their emotions. Even more so, experimental observations have undermined the relevance of the axioms of the theory of the expectancy of utility. Thus, defenders of classical finance have become incapable of neglecting the many criticisms that have been addressed to them, and how the agents formulate their choices instead of using assumptions that specify how they should behave. This is how behavioral finance caused a lot of ink flow. Especially since events have occurred and have increased the attractiveness of this new approach such as the bursting of the internet bubble in 2000, the awarding of the Nobel Prize in economics to Daniel Kahneman and Vernon Smith in 2002 who developed the theory of perspectives. The latter relates the impact of psychological biases on the decision-making of economic agents when they face risky choices. Numerous studies have challenged the theory of utility expectancy and led to the emergence of alternative approaches such as the one proposed by Kahneman and Tversky in 1979. These works exceed the scope of finance and lays the foundation for an alternative financial theory in which individual behavior is no longer rational. The goal of behavioral finance was to find insights into the many market phenomena or portfoliochoice behaviors that are referred to as biases or anomalies. Behavioral finance is a new stream of research based on the psychology of the investor. This current is based on fundamental points in particular, the limit of the rationality of the investor and the influence of the decisions by the beliefs and the emotions. This means that individuals use reasoning shortcuts called heuristics in their information processing process.

In this article, the goal is to detect the existence of behavioral biases and determine their impact on the decisions made by investors. We relied on a quantitative study that was conducted on a sample of 30 people composed of traders and portfolio managers of equity securities training in management companies in Morocco. In fact, several studies of this kind have been carried out to detect these psychological biases. The first study is of Kahneman and Tversky in 1974. Through their research, they were able to deduce that the agents do not have the cognitive capacities to be able to make their decisions on the financial markets and in a rational way. These individuals operate shortcuts of reasoning to simplify reality and create more comprehensible models. The main heuristics that have been studied are representativeness, anchoring and availability. Debondt and Thaler had studied the impact of overconfidence on decision-making. According to them, investors who tend to overstate their abilities and knowledge underestimate the risk it takes with their decisions. Another study, of Fried et al in 1970, states that in the case of lack of confidence, managers tend to follow the strategy of the most successful person among them. This trend is even more accentuated when managers are paid according to their performance. As for our study, the results obtained are that managers of securities portfolios and traders are influenced by the psychological biases during their decision- making process, including anchoring bias, status-quo, sheep behavior, mental accounting loss aversion etc. Especially the cultural bias, since it has never been treated before and is a product of our Moroccan culture and very present and has an impact on decision- making. In addition, the research model we have constructed has shown that the psychological biases that were studied with the exception of representativeness bias influence $77 \%$ of investors' decision-making. 
Financial Markets, Institutions and Risks, Volume 3, Issue 1, 2019

ISSN (online) - 2521-1242 ISSN (print) - 2521-1250

\section{References}

1. -Albouy, M., Charreaux, G. (2005). La finance comportementale ou l'émergence d'un nouveau paradigme dominant. Revue Française de Gestion, 157, 139-143.

2. -Barberis N., Shleifer A., Vishny R. W. (1998). A model of investor sentiment. Journal of Financial Economics, 49, 307-343.

3. Barberis N., Thaler R. (2003). A Survey of Behavioral Finance. In Handbook of the Economics of Finance, G.M. Constantinides, M. Harris et R. Stulz eds, 1054- 1123.

4. -Barberis, N., Huang, M. (2001). Mental accounting, loss aversion and individual stock returns. Journal of Finance, 56, 1247-1292.

5. -Barraud, C. (2010). De l'efficience des marchés financiers à la finance comportementale, Analyse financière, 25, 59-62.

6. Ben Bouheni, F. (2009). La réaction du marché financier face au biais d'excès deconfiance.

7. -Bernard V., Thomas J. (1989). Post-Earnings-Annoucement Drift: Delayed Price Response or Risk Premium? Journal of Accounting Research, 27, Supplement, 1-36.

8. -Boubaker, A., Bouattour, B. (2008). Détection du comportement mimétique sur le marché boursier tunisien, Revue Tunisienne d'Economie et de Gestion, n²6, Vol. XXVI, 293-319.

9. -Broihanne, M., Merli, M. \& Roger, P. (2004). Finance comportementale. Economica.

10. -DeBondt W. et Thaler R. (1994). Financial Decision-Making in Mar- kets and Firms: A Behavioral Perspective, NBER Working Paper No. W4777.

11. -Fama E. F. (1970). Efficient Capital Markets: A Review of Theory and Empirical Work. Journal of Finance, 25, 2, 383-417.

12. -Fama E. F. (1991). Efficient Capital Markets: II. Journal of Finance, 46, 5, 1575- 1617.

13. -Fama E. F. (1998). Market efficiency, long-term returns, and behavioral finance. Journal of Financial Economics, 49, 283-306.

14. -Fama E. F., Fisher L., Jensen M., Roll R. (1969). The adjustment of stock prices to new information. International Economic Review, 10, 1-21.

15. -Fama E. F., French K. (1992). The cross-section of expected stock returns. Journal of Finance, 47, 2, pp. 427-465.

16. -Fama E. F., French K. (1993). Common risk factors in the returns on stocks and bonds. Journal of Financial Economics, 33, 3-56.

17. -Fama E. F., French K. (1996). Multifactor Explanation of Asset Pricing Anomalies. Journal of Finance, $51,55-84$.

18. -Fama E. F., French K., (1988). Permanent and temporary components of stock prices. Journal of Political Economy, 96, 246-273.

19. -Fama, E.F. (1976). Foundations of finance: portfolio decisions and securities prices. New York: Basic Books.

20. -Hirshleifer D. \& Siew Hong T. (2008). Thought and Behavior Contagion in Capital Markets, Merage School of Business, UC Irvine.

21. -Hirshleifer D. (2001). Investor psychology and asset pricing. Journal of Finance, 64, 1533-1597.

22. -Kahneman, D., \& Tversky, A. (1979). Prospect theory: an analysis of decision under risk. Econometrica, 47, 263-291.

23. -Kahneman, D., Slovic, P. \& Tversky, A. (1982). Intuitive predictions: biases and corrective procedures in judgment under uncertainty: heuristics and biases. Cambridge University Press, London CUP.

24. -Kezzar, R. (2017). La théorie comportementale du portefeuille comme alternative au paradigm classique moyenne-variance: revue de la literature, ور العلوم التجارية مجلة العلوم الاقتصادية و التسيير 2017, p. 33

25. -Mangot, M. (2004). Les comportements en bourse, 6 erreurs psychologiques qui cô̂tent chers, Gualino éditeur, $117 \mathrm{p}$.

26. -Mangot, M. (2005). Psychologie de l'investisseur et des marchés financiers, éd. Dunod, 291p.

27. -Markowitz, H. (1952b). The utility of wealth, Journal of political Economy, 60, 151-158.

28. -Marsat, S. (2006). Approches de la genèse des comportements mimétiques sur le marché des actions, Gestion et management. Université d'Auvergne - Clermont- Ferrand I.

29. -Midy F. (1996). Validité et fiabilité des questionnaires d'évaluation de la qualité de vie. Une étude appliquée aux accidents vasculaires cérébraux, Document de travail, Université de Bourgogne, p.9

30. -Schinckus, C. (2009). La finance comportementale ou le développement d'un nouveau paradigme, Ed. Sc. Humaines, Revue d'Histoire des Sciences Humaines, 2009/1 n 20 pages 101 à 127

31. -Sharpe, W. (1964). Capital asset pricing: a theory of market equilibrium under conditions of risk. Journal 
of finance, 19, 425-442.

32. -Shefrin H., Thaler R. H. (1988). The Behavioral Life-Cycle Hypothesis. Economic Inquiry, 26, 609-643.

33. -Shefrin, H. \& Statman, M. (1985). The disposition to sell winners too early and ride losers too long: Theory and evidence. The journal of finance, 3, 777-790.

34. Shefrin, H. \& Thaler, R.H., (1982). Mental accounting saving, and self-control. Choice over time, éd.G. Loewenstein and J. Elster, 287-330.

35. -Shiller R. (2006). Tools for Financial Innovation: Neoclassical versus Behavioral Finance. The Financial Review, 41, 3, 1-8.

36. -Shiller R. J. (1981). Do stock prices move too much to be justified by subsequent changes in dividends? American Economic Review, 71, 421-498.

37. -Shiller R. J. (1984). Stock prices and social dynamics. Brookings Papers on Economic, Activity Review 2, 457-498.

38. -Shiller R. J. (1999). Human behavior and the efficiency of the financial system. In: Taylor J., Woodford M., (Eds.), Handbook of Macroeconomics. Elsevier, Amsterdam.

39. -Shiller R. J., (2005). Irrational Exuberance. 2nd edition. Princeton University Press.

40. -Shleifer A. (2000). Inefficient markets: An introduction to behavioral finance. Oxford University Press.

41. -Shleifer A., Summers L. H. (1990). The noise trader approach to finance. Journal of Economic Perspectives, 4, 19-33.

42. -Shleifer A., Vishny R. W. (1997). The Limits of Arbitrage. Journal of Finance, 52, 1, 35-55.

43. -Simon, Y. (1985). Techniques financières internationales, Collection Gestion, Série: Politique générale, finance et marketing, Economica, 431p.

44. -Stracca, L. (2004). Behavioral Finance and asset prices: where do we stand? Journal of economic psychology, 25, 373-405.

45. -Susskind, A. (2005). La finance comportementale, éd De Boeck \& Larcier, 101p.

46. -Thiétart R.A. \& al., (2010). Méthodes de recherche en management », 4 ed, Dunod, 647 p.

47. -Tversky, A. (1969). Intransitivity of preferences. Psychological Review, 79, 281- 299.

48. -Von Neumann, J., \& Morgentern O. (1947). Theory of games and economic behavior. Princeton University Press.

49. -Williams J.B. (1939). Theory of Investment value, Harvard University Press, p.19. 